\title{
OPTIMAL POLICY FOR FINANCIAL MARKET LIBERALIZATIONS: DECENTRALIZATION AND CAPITAL FLOW REVERSALS*
}

\author{
Theo Eicher \\ University of Washington \\ Stephen J. Turnovsky \\ University of Washington \\ Uwe Walz \\ University of Tübingen
}

July 1999

\begin{abstract}
Financial market liberalizations are an integral part of economic development. While initial booms in investment and output are commonly seen as signs of successful deregulation, they often reverse at a later stage as international capital flows turn negative and economic growth slows markedly. Such reversals of fortunes have commonly been attributed to incorrect policies that supposedly followed the initial, appropriate measures. It is unclear, however, if capital flow reversals are actually the result of policy reversals, or if they occur as part of the normal transition when financial liberalization is accompanied by a single sub-optimal policy. The later hypothesis has not been explored in the theoretical literature.

We construct a general equilibrium growth model of a small open economy, in which capital flow reversals are the result of a single, sub-optimal policy imposed at the beginning of the financial liberalization. We show how improper taxation of foreign borrowing initially leads to strong growth fueled by an investment boom and foreign borrowing. Still along the transition, however, the model predicts that capital flows must reverse endogenously at a later stage, as the debt burden rises and the country specific risk premium increases. Our data on the Latin American and East Asian countries provide strong support for our hypothesis.

"Much of the work for this paper was done while Eicher enjoyed the hospitality of Tübingen University. He gratefully acknowledges support provided by the von Humboldt Foundation. We thank Elke Speidel-Walz at Deutsche Bank Research for data support.
\end{abstract}




\section{Introduction}

Recent events in East Asia and Latin America highlight the significance of foreign capital flow reversals and their contributions to investment fluctuations and capital account imbalances. One-time policy changes, such as financial liberalizations, have become associated with initial periods of strong economic growth and "excessive" capital inflows, followed by major contractions and capital outflows at a later stage. For example, Thailand's financial liberalization in the early 1990s effectively lowered tax rates and the cost of foreign capital specifically to attract capital inflows. This initially caused an investment and growth boom that was financed largely by foreign capital. But eventually, the country's indebtedness became a source of concern for lenders. The pressure on the balance of payments increased, together with lending rates, to reflect the perceived increased country risk, and a balance of payments crisis leading to net capital outflows ensued. ${ }^{1}$

The objective of this paper is to show how such capital flow reversals can be generated as part of the intrinsic dynamic adjustment resulting from a unique initial policy event, such as financial liberalization. Conventional small open economy growth models that are characterized by onedimensional transitional paths cannot produce such an adjustment path, since such models require at least two separate and offsetting policy shocks in order to account for both capital inflows and outflows. $^{2}$ To obtain such reversals in accumulation as part of the internal dynamics following a one-time policy event requires that the transitional adjustment path be of higher dimension (nonlinear). One type of model that may yield precisely such nonlinear transitional adjustment paths is the non-scale growth model, introduced by Jones (1995a) and extended to the small open economy

\footnotetext{
1 The events are well documented in the literature, see for example Guitian (1998). Fischer (1998) underlines the particularly detrimental effects of the 1993 financial reform that aggressively targeted foreign borrowing.

${ }^{2}$ See e.g. Bond, Wang, and Yip (1996), Turnovsky (1997, Chapter 5).
} 
by Eicher and Turnovsky (1999b). We apply such a model to examine specifically the dynamic adjustments generated by a financial liberalization.

Financial liberalizations are an integral part of economic development. Most industrialized economies have relied on state-controlled financial intermediation for significant periods, and in many developing countries quasi-governmental financial institutions still dominate the financial sector today. To maintain this historical perspective we commence by analyzing the central planner's version of the non-scale growth model of Eicher and Turnovsky (1999b). Subsequently, we consider how a country could optimally decentralize its financial operations and thereby move to a decentralized market economy. The solution proposed by the model yields not only novel economic implications, but also contributes to the broad discussion about the frequently observed economic instability that has followed numerous real world financial liberalizations.

The increase in the dimensionality of the underlying dynamic adjustment, necessary to generate capital flow reversals, is achieved by the introduction of two key features: the absence of scale effects in the equilibrium growth rates, and the presence of imperfections in the international capital market. Both aspects are important on the basis of theoretical and empirical considerations. First, in terms of the theoretical considerations, an important drawback of the first generation of endogenous growth models is that they may exhibit "scale effects." This term is used when variations in the levels of key variables such as investment rates and research effort exert permanent influences on national growth rates (see Jones, 1995a; Young, 1998; Segerstrom, 1998, and Eicher and Turnovsky, 1999a). However, these theoretical predictions run counter to recent empirical evidence, and have been qualified extensively in so called non-scale growth models. ${ }^{3}$ Non-scale growth models have the added advantage that they are consistent with steady-state balanced growth under far less

\footnotetext{
${ }^{3}$ Evidence against the presence of scale effects is provided by Backus, Kehoe, and Kehoe (1992), Jones (1995b), and Stokey and Rebelo (1995).
} 
restrictive conditions than the knife-edge technologies of the endogenous growth models (see Solow, 1994).

The second motivation is empirical and relates to the flow of international capital. We assume that the economy faces a restricted world capital market, in the form of an upward sloping supply schedule of funds, reflecting the borrowing premium that highly indebted countries must remit to foreign creditors. Such representations of international credit market imperfections were originally introduced by Bardhan (1967), and subsequently motivated more formally by Eaton and Gersovitz (1981, 1989) and Kletzer (1984), on the basis of asymmetric information and default risk. The assumption is intended to reflect the reality that international capital markets require borrowing premiums to compensate for sovereign risk, and is particularly appropriate when considering developing economies. Empirical support for such a relationship is provided by Edwards (1984).

In order to avoid the above-described capital flow reversals, financial liberalization must be accompanied by specific policy measures. This is because the economy features two externalities: one in the production technology, necessary to sustain per capita growth, and the other arising from the upward sloping supply curve of debt. To correct for these externalities, we find that an optimal financial liberalization must be accompanied by an optimal tax on both foreign borrowing and consumption, while subsidizing domestic capital accumulation. Intuitively, financial liberalization increases the openness of the capital account, which increases foreign borrowing at the cost of domestic capital accumulation. However, the increase in foreign debt raises the country's borrowing premium to foreign investors, and the decline of domestic assets relative to the debt level increases the risk even further. Consumption needs to be curtailed to save for domestic investment and to finance the subsidy on domestic capital accumulation.

We show that if an economy's financial sector is decentralized with an inadequately low tax on foreign borrowing, the country initially finances an investment and growth boom with foreign debt. 
However, the subsequently increasing interest payments leave less output for domestic investment, and further raise the country's level of indebtedness, thereby raising the country-specific borrowing premium. With the higher premium, the costs of existing debt and new borrowing rise even more. Eventually the economy must contract to repay its debt and to slow the boom fueled by foreign capital. At this time the country experiences significant capital outflows. Our results do not argue against financial liberalization per se. Instead, we highlight that decentralization must be accompanied by the appropriate institutional structure, such as a government body to oversee borrowing activity and to set appropriate tax rates, so as to generate the correct domestic investment incentives. 
We compare the implications of our theoretical model with the experiences of three Asian countries (Thailand, Indonesia, and South Korea) and Mexico. Thereby we focus on four prominent cases in which recently capital flow reversals have been observed. These countries experienced various measures of financial liberalization at the beginning of the 1990s. While the period in which financial liberalization took place was the same for all four countries, the concrete measures, as well as the precise dates when these measures were set in place, differ among these countries. The crises in these countries occurred at different points in time. Whereas Mexico experienced a crisis in the external sector in 1994/1995, Indonesia, South Korea and Thailand experienced their crises in the second half of 1997. In the period after financial liberalization, macroeconomic performance of the four countries under consideration was remarkably similar. With a short policy lag, financial liberalization led to pronounced capital inflows (most notably private portfolio and direct foreign investment) and hence to higher levels of debt. This period of foreign borrowing was accompanied by significant expansion of output. In all cases, an eventual negative growth rate of fixed investment preceded the crisis, which culminated in a currency crisis and a sharp reversal of capital inflows. Thus, the observed patterns in these countries mirror the time path predicted by our model in a striking manner.

The rest of the paper proceeds as follows. Section 2 lays out the structure of the small open economy. Section 3 characterizes the equilibrium dynamics in a centrally planned economy, while in Section 4 we review the decentralized economy. Section 5 examines optimal policy and Section 6 supplements the analytical results with empirical data from recent financial liberalizations and crises in East Asia. Our main findings are briefly summarized in Section 7.

\section{The Analytical Framework}


We begin by considering a small open economy that consumes and produces a single traded commodity. Each individual is identical and is endowed with a fixed quantity of labor, $L_{i}$. Labor is fully employed so that total the labor supply equals the size of the population, $N$, which grows at the steady rate $N=n N$. Individual domestic output, $Y_{i}$, is determined by the individual's private capital stock, $K_{i}$, his labor supply, $L_{i}$, and the aggregate capital stock $K=N K_{i}$. Assuming a Cobb-Douglas production function, individual output is determined by

$$
Y_{i}=\alpha^{\prime} L_{i}^{1-\sigma} K_{i}^{\sigma} K^{\eta} \equiv \alpha K_{i}^{\sigma} K^{\eta} \quad 0<\sigma<1, \eta \stackrel{>}{<} 0 .
$$

This formulation is similar to the earliest endogenous growth model of Romer (1986). The spillover can be motivated in various ways. One is to interpret $K$ as knowledge capital, as Romer suggested. Another is to assume $N$ specific inputs (subscripted by $i$ ) with aggregate $K$ representing an intraindustry spillover of knowledge. A negative exponent on $K$ can be interpreted as reflecting congestion externalities.

Each factor of production has positive, but diminishing, marginal physical productivity. To assure the existence of a competitive equilibrium we follow Romer (1986) and require the production function to exhibit constant returns to scale in the two private factors, $K_{i}, L_{i}$. But in contrast to the standard neoclassical growth model, total returns to scale, $1+\eta$, increase or decrease according to whether the spillover from aggregate capital, $\eta \stackrel{>}{<} 0$. Eicher and Turnovsky (1999a) prove that the existence of a positive balanced growth equilibrium under nonconstant returns to scale requires that the production function be (in general) Cobb-Douglas, as assumed in (1a).

Aggregate consumption in the economy is denoted by $C$, so that per capita consumption at time $t$ is $C / N=C_{i}$, yielding the individual agent utility over an infinite time horizon represented by the intertemporal isoelastic utility function:

$$
\Omega \equiv \int_{0}^{\infty}(1 / \gamma)(C / N)^{\gamma} e^{-\rho t} d t ; \quad-\infty<\gamma<1
$$


Individual agents accumulate physical capital, with expenditure on a given change in the capital stock, $I_{i}$, involving adjustment (installation) costs that we incorporate in the quadratic (convex) function

$$
\Phi\left(I_{i}, K_{i}\right) \equiv I_{i}+h I_{i}^{2} / 2 K_{i}=I_{i}\left(1+h I_{i} / 2 K_{i}\right) .
$$

The linear homogeneity of this function is necessary for the steady-state equilibrium to exhibit sustained growth. For simplicity we assume that the capital stock does not depreciate, so that the individual's net rate of capital accumulation is given by

$$
K_{i}^{Y}=I_{i}-n K_{i}
$$

Agents may borrow internationally on a world capital market. The key institutional factor that we wish to take into account is that the creditworthiness of the economy influences its cost of borrowing from abroad. Essentially we assume that world capital markets assess an economy's ability to service debt and its associated default risk. Much like the Standard and Poor's credit ratings, we assume that the key indicator of risk is the country's debt-capital (equity) ratio. As a result, the interest rate countries are charged on world capital markets increases with this ratio. This leads to the upward sloping supply schedule for debt, expressed by assuming that the aggregate borrowing rate, $r[Z / K]$, charged on foreign debt, $Z$, is of the form:

$$
r[Z / K]=r^{*}+\omega[Z / K] \omega^{\prime}>0
$$

where $r^{*}$ denotes the exogenously given world interest rate, for example given by the London Interbank Borrowing Rate (LIBOR), and $\omega($.) denotes the country-specific borrowing premium that increases with the nation's debt-capital ratio. The homogeneity of the relationship is required to sustain a balanced growth equilibrium.

Several variants of the borrowing constraint can be found in the literature. The original formulation by Bardhan (1967) expressed the borrowing premium in terms of the absolute stock of 
debt, although this cannot sustain a balanced growth equilibrium. ${ }^{4}$ Sachs (1984) and Cooper and Sachs (1985) argue in support of a relative form of borrowing premium, as specified in (2). They suggest how a country, by adopting growth-oriented policies, can shift the upward-sloping supply curve outward, so that at each level of debt a lower borrowing premium is charged. This effect can be incorporated by assuming that the borrowing premium depends upon the level of debt relative to some measure of debt-servicing capacity, such as capital or output that depends upon capital; see also van der Ploeg (1996). Edwards (1984) provides empirical evidence that finds a robust and significant positive relationship between the spread over LIBOR (e.g. $\left.r^{*}\right)$ and the debt-GNP ratio.

While (2) is plausible and suffices for our purposes, it should be interpreted as a reduced form relationship, one that implicitly assumes the existence of risk. Eaton and Gersovitz (1989) show that whether or not the presence of default risk leads to an upward sloping supply of capital, depends upon the nature of the penalty function in the event of default. Aizenman and Turnovsky (1999) show how an upward sloping supply curve will obtain in the case of an economy facing default risk and probability of bailout, as long as the (positive) resource costs necessary to enforce the agreed repayment scheme in the event of partial default is not too large. Finally, in specifying (2) we are viewing the imperfection of the bond market from the standpoint of a borrowing nation. This seems natural in the sense that it is the debtor nation that is the source of the underlying risk.

The relationships, (1a), (1c) and (1d) relate to individual agents. Our objective is to analyze the dynamics of the aggregate economy and thus it is necessary to define the relevant aggregate quantities. First, summing the individual production functions, (1a), over the $N$ agents, the aggregate production function is

$$
Y=\alpha K^{\eta+\sigma} N^{1-\sigma} \equiv \alpha K^{\sigma_{K}} N^{\sigma_{N}}
$$

\footnotetext{
${ }^{4}$ Obstfeld (1982), Bhandari, Haque, and Turnovsky (1990), Fisher (1995), and Turnovsky (1997, Chapter 2) provide more recent applications of the Bardhan formulation.
} 
where $\sigma_{N} \equiv 1-\sigma$ represents the share of labor in aggregate output, and $\sigma_{K} \equiv \sigma+\eta$ identifies the share of capital in aggregate output. Thus $\sigma_{K}+\sigma_{N}=1+\eta$ measures total returns to scale of the (social) aggregate production function.

Long-run equilibrium is a balanced growth path along which aggregate output and aggregate capital are assumed to grow at the same constant rate, so that the aggregate output-capital ratio remains unchanged. Taking percentage changes of (3a) and imposing the long-run condition of a constant capital-output ratio, the long-run equilibrium growth of capital and output, $g$, is given by

$$
g \equiv\left(\frac{\sigma_{N}}{1-\sigma_{K}}\right) n .
$$

Equation (4) exhibits the key characteristic of non-scale growth models, namely that the long-run growth rate depends upon the technological elasticities in conjunction with the population growth rate, and is independent of policy. It is also apparent from (4) that the balanced growth rate is positive if and only if $\sigma_{K}<1$. Under constant returns to scale, the equilibrium rate of growth of the economy equals the rate of population growth, $n$. Otherwise, $g$ exceeds $n$ or is less than $n$, implying positive or negative per capita growth, according to whether returns to scale are increasing or decreasing, $\eta \geq 0$.

Summing over the individual capital stocks and investment leads to the aggregate investment costs

$$
\Phi(I, K)=I+h I^{2} / 2 K=I(1+h I / 2 K) .
$$

In addition, noting that $K^{Y}=N K_{i}^{Y}+n N K_{i}$, and combining with (1d), the aggregate rate of capital accumulation is given by

$$
K^{X}=I
$$

Finally, the nation's aggregate rate of debt accumulation, its current account deficit, is described by 


$$
\dot{Z}=C+I\left(1+\frac{h}{2} \frac{I}{K}\right)-\alpha K^{\sigma_{K}} N^{\sigma_{N}}+r\left\lfloor\frac{Z}{K}\right\rfloor Z .
$$

\section{The Centrally Planned Economy}

Since all financial liberalizations are essentially decentralizations of a state-run financial sector, it is convenient to begin by considering a centrally planned economy. This serves as a benchmark against which the decentralized economy can be compared, and thereby will shed light on the optimal tax structure as part of the financial liberalization program.

We assume that the central planner's objective is to choose the aggregate rates of consumption, $C$, investment, $I$, capital accumulation, $K^{Y}$, and debt accumulation, $Z$, to maximize the utility of the representative agent, (1b), subject to the aggregate accumulation equations (3c) and (5). The Hamiltonian to this maximization problem is represented by:

$$
\mathrm{H} \equiv \frac{1}{\gamma}\left(\frac{C}{N}\right)^{\gamma} e^{-\rho t}-\lambda e^{-\rho t}\left\lfloor C+I\left(1+\frac{h}{2} \frac{I}{K}\right)-\alpha K^{\sigma_{K}} N^{\sigma_{N}}+r\left[\frac{Z}{K}\right] Z-\not{Z}\right]+q^{\prime} e^{-\rho t}\left[I-K^{X}\right]
$$

where $\lambda$ is the shadow value (marginal utility) of aggregate wealth in the form of internationally traded bonds and $q^{\prime}$ is the shadow value to the agent of the aggregate capital stock. Analysis of the model is simplified by using the shadow value of wealth as numeraire. Consequently $q \equiv q^{\prime} / \lambda$ measures the market value of capital in terms of the (unitary) price of foreign debt.

The relevant optimality conditions with respect to $C$ and $I$ are respectively

$$
\begin{aligned}
& \frac{C^{\gamma-1}}{N^{\gamma}}=\lambda \\
& 1+h \frac{I}{K}=q
\end{aligned}
$$

Condition (6a) equates the marginal utility of consumption to the shadow value of wealth, while equation (6b) sets the marginal cost of an additional unit of investment, which includes the marginal 
installation cost $h I / K$, to the market value of capital. The latter relation may be immediately solved to yield the following expression for growth rate of the aggregate capital stock,

$$
\frac{K^{Y}}{K}=\frac{I}{K}=\frac{q-1}{h} \equiv \phi
$$

Thus, starting from an initial level $K_{0}$, the national stock of capital at time $t$ is $K(t)=K_{0} e^{\int_{0}^{t} \phi(s) d s}$.

The optimality conditions with respect to debt and capital lead to the arbitrage relationships:

$$
\begin{gathered}
\rho-\frac{\lambda \mathrm{Y}}{\lambda}=r\left[\frac{Z}{K}\right]+r^{\prime}\left[\frac{Z}{K}\right] \cdot \frac{Z}{K} \\
\frac{\sigma_{K} Y}{q K}+\frac{\dot{\Phi}}{q}+\frac{(q-1)^{2}}{2 h q}+\frac{r^{\prime}[Z / K]}{q}\left(\frac{Z}{K}\right)^{2}=r\left[\frac{Z}{K}\right]+r^{\prime}\left[\frac{Z}{K}\right] \cdot \frac{Z}{K}
\end{gathered}
$$

Equation (6c) is the standard Keynes-Ramsey consumption rule, equating the marginal return on consumption to the marginal cost of borrowing. It is important to observe that in determining the latter, the central planner recognizes that increasing his stock of debt raises the cost of borrowing. Likewise, (6d) equates the return on domestic capital to the marginal cost of borrowing. The return on domestic capital consists of four components. The first is the contribution to output per unit of installed capital, (valued at the price $q$ ), while the second term is the rate of capital gain. The third element, which equals $(q I-\Phi) / q K$, reflects the fact that an additional benefit of a higher capital stock is to reduce the installation costs associated with new investment. The fourth element stems from the fact that an increase in capital lowers the debt cost, thereby providing a further benefit to investing in capital.

Finally, in order to ensure that the agent's intertemporal budget constraint is met, the following transversality conditions must be imposed:

$$
\lim _{t \rightarrow \infty} \lambda Z e^{-\rho t}=0 ; \quad \lim _{t \rightarrow \infty} q^{\prime} K e^{-\rho t}=0
$$

The transversality condition on debt is equivalent to the national intertemporal budget constraint. 
Given the returns to scale properties of the aggregate production function described in (3), it is necessary to normalize key variables in order to analyze the transitional dynamics of the economy about its long-run stationary growth path. Thus we express the system in terms of the market price of installed capital, $q$, and the following stationary variables:

$$
c \equiv \frac{C}{N^{\left(\sigma_{N} /\left(1-\sigma_{K}\right)\right)}} ; \quad k \equiv \frac{K}{N^{\left(\sigma_{N} /\left(1-\sigma_{K}\right)\right)}} ; \quad z \equiv \frac{Z}{N^{\left(\sigma_{N} /\left(1-\sigma_{K}\right)\right)}} .
$$

Under standard conditions of constant social returns to scale, $\sigma_{N}+\sigma_{K}=1$, the quantities in (8a) reduce to standard per capita quantities, i.e. $c=C / N, k=K / N, z=Z / N$. Otherwise they represent "scale-adjusted" per capita quantities. 


\subsection{Macrodynamic Equilibrium}

Differentiating the quantities given in (8a) and recalling (4) implies the following relationships:

$$
\frac{\dot{C}}{c}=\frac{\dot{C}}{C}-g ; \quad \frac{k^{Y}}{k}=\frac{K^{Y}}{K}-g ; \quad \frac{\not{X}}{z}=\frac{\not{Z}}{Z}-g
$$

If we combine the time derivative of $(6 a)$ with $(6 c)$ we obtain the growth rate of scale-adjusted per capita consumption

$$
\frac{\dot{Y}}{c}=\frac{r[z / k]+r^{\prime}[z \mid k] \cdot(z \mid k)-\rho-\gamma_{n}}{1-\gamma}-\left(\frac{\sigma_{N}}{1-\sigma_{K}}\right) n \equiv \psi-g .
$$

The growth rate of scale-adjusted capital can be obtained by combining (7) with (8b):

$$
\frac{k^{\dot{Y}}}{k}=\frac{q-1}{h}-\left(\frac{\sigma_{N}}{1-\sigma_{K}}\right) n \equiv \phi-g,
$$

while (6d) provides the evolution of the relative price of capital:

$$
\dot{q}=\left(r[z / k]+r^{\prime}[z / k] \cdot(z / k)\right) q-r^{\prime}[z / k] \cdot(z / k)^{2}-\frac{(q-1)^{2}}{2 h}-\alpha \sigma_{K} k^{\sigma_{K}-1} .
$$

Finally, combining (8b) with (5), the dynamics of the scale-adjusted per capita stock of debt is given by

$$
\dot{z}=(r[z / k]-g) z-\alpha k^{\sigma_{K}}+c+\left(\frac{q^{2}-1}{2 h}\right) k .
$$

The system of equations (9a) - (9d) is an autonomous system in the four variables $c, k, z, q$, all of which are linked in an interdependent fourth order system. All variables in the system are subject to transitional dynamics. 
The steady state growth path is obtained when $\dot{c}=k=\not{Y}=\dot{X}=0$, so that the corresponding steady state values of $c, k, z, q$, denoted by tildes, are determined by ${ }^{5}$ :

$$
\begin{gathered}
\frac{r[\tilde{z} / \tilde{k}]+r^{\prime}[\tilde{z} / \tilde{k}] \cdot(\tilde{z} / \tilde{k})-\rho-\gamma n}{1-\gamma}=g \\
\tilde{q}=1+h\left(\frac{\sigma_{N}}{1-\sigma_{K}}\right) n=1+h g \\
\frac{\alpha \sigma_{K} \tilde{k}^{\sigma_{K}-1}}{\tilde{q}}+\frac{(\tilde{q}-1)^{2}}{2 h \tilde{q}}+\frac{\left.r^{\prime}[\tilde{z} / \tilde{k}] \tilde{z} / \tilde{k}\right)^{2}}{\tilde{q}}=r\left[\frac{\tilde{z}}{\tilde{k}}\right]+r^{\prime}\left[\frac{\tilde{z}}{\tilde{k}}\right] \cdot \frac{\tilde{z}}{\tilde{k}} \\
\tilde{c}+\left(\frac{\tilde{q}^{2}-1}{2 h}\right) \tilde{k}-\alpha \tilde{k}^{\sigma_{K}}+(r[\tilde{z} / \tilde{k}]-g)=0 .
\end{gathered}
$$

This steady state has a simple recursive structure. First, the steady-state price of installed capital is determined by (10b), so that the equilibrium growth rate equals $g$. Given the non-scale nature of our model, the restricted access to the world financial market has no adverse impact on the country's long-run growth rate of output. In contrast to some previous small open economy growth models the long-run domestic consumption grows at the same rate as does output. ${ }^{6}$ This equality is achieved through the adjustment in the country's debt to capital ratio, $\tilde{z} / \tilde{k}$, and hence in the cost of borrowing. Having determined both $\tilde{q}$ and $\tilde{z} / \tilde{k}$, (10c) determines the scale adjusted capital-labor ratio, $\tilde{k}$, such that the after-tax return on capital equals the marginal cost of debt. Finally, given $\tilde{q}$, $\tilde{z} / \tilde{k}$, and $\tilde{k},(10 \mathrm{~d})$ determines the equilibrium scale-adjusted per capita consumption, $\tilde{c}$. Following Eicher and Turnovsky's (1999b) discussion for the decentralized economy, we can identify weak conditions under which the fourth order dynamic system (9) has two stable eigenvalues, so that with $q$ and $c$ being free to jump instantaneously, the centralized economy is saddlepath stable.

\footnotetext{
5 The equilibrium growth rate must be consistent with the transversality condition. By direct calculation, this can be shown to reduce to: $r[\tilde{z} / \tilde{k}]+r^{\prime}[\tilde{z} / \tilde{k}] \cdot(\tilde{z} / \tilde{k})>g$. Substituting from (10a), this can be expressed in terms of exogenous parameters: $\gamma<\rho\left(1-\sigma_{K}\right) n /\left(\sigma_{N}+\sigma_{K}-1\right)$. When this condition is met, a unique steady-state equilibrium exists. ${ }^{6}$ Such differential growth rates occur if the small open economy faces a perfect world capital market and its labor supply is inelastic; see Turnovsky (1996) for an example.
} 
Having characterized the equilibrium of a centrally planned economy, we can ask if it might be decentralized in such a way that the socially optimal levels of foreign borrowing and domestic investment are maintained, but agents act only in their own best self interest. To compare the centralized economy to the decentralized, we review the latter, as discussed by Eicher and Turnovsky (1999b), noting how individual agents neglect the two externalities we have introduced.

\section{The Decentralized Economy}

The representative agent's decisions in the decentralized economy are to choose his individual consumption, $C_{i}$, rate of investment, $I_{i}$, and rates of accumulation of capital $K_{i}$, and debt $Z_{i}$ to maximize his utility function (1b), subject to his accumulation of capital (1d) and his flow budget constraint, now expressed as

$$
\ddot{Z}_{i}=\left(1+\tau_{c}\right) C_{i}+I_{i}\left[1+(h / 2)\left(I_{i} / K_{i}\right)\right]-\left(1-\tau_{y}\right) Y_{i}+\left[\left(1+\tau_{z}\right) r[Z / K]-n\right] Z_{i}-T_{i}
$$

The individual constraint, (11), differs from the aggregate constraint, (5) in the centrally planned economy in several respects. First, current production is taxed at rate $\tau_{y}$, debt payments are taxed at the rate $\tau_{z}$, while consumption is taxed at rate $\tau_{c}$, and all taxes are rebated as lump sum transfers, $T_{i}$. Because of the growing population, part of the costs of debt is incurred by future agents, reducing the cost of debt to the representative agent by the rate of population growth, $n$.

It is important to emphasize that in performing his optimization, the representative agent takes the interest rate as given. This is because the interest rate facing the debtor nation, as reflected in its upward sloping supply curve of debt, is a function of the economy's aggregate debt to capital ratio, which the individual agent in making his decisions assumes he is unable to influence.

Performing the optimization, the optimality conditions with respect to $C_{i}$ and $I_{i}$ are

$$
\begin{aligned}
& C_{i}^{\gamma-1}=\lambda_{i}\left(1+\tau_{c}\right) \\
& 1+h \frac{I_{i}}{K_{i}}=q_{i}
\end{aligned}
$$


where $\lambda_{i}$ is the agent's marginal utility of his own (in contrast to the aggregate) wealth, and $q_{i}$ is defined analogously to $q$. With the economy comprising $N$ identical individuals, $\lambda_{i}=N \lambda$ and $q_{i} \equiv q$. The equilibrium conditions with respect to debt and capital can now be modified to ${ }^{7}$

$$
\begin{aligned}
& \rho-\frac{\lambda \mathrm{Y}}{\lambda}=\left(1+\tau_{z}\right) r[Z / K] \\
& \left(1-\tau_{y}\right) \frac{\sigma Y_{i}}{q K_{i}}+\frac{\dot{X}}{q}+\frac{(q-1)^{2}}{2 h q}=\left(1+\tau_{z}\right) r\left\lfloor\frac{Z}{K}\right\rfloor
\end{aligned}
$$

which reflect (i) the presence of taxes, and (ii) the fact that the agent takes the interest rate as given.

As noted, all tax revenues are rebated. Aggregating over the $N$ individuals, this implies the government budget constraint:

$$
T=r \tau_{z} Z+\tau_{y} \alpha K^{\sigma_{K}} N^{\sigma_{N}}+\tau_{c} C
$$

Summing (11) over the individuals and combining with (12) leads to the economy's net rate of accumulation of debt:

$$
Z=C+I[1+(h / 2)(I / K)]-\alpha K^{\sigma_{K}} N^{\sigma_{N}}+r[Z / K] Z
$$

which is identical to the relationship in the centrally planned economy.

\subsection{Macrodynamic Equilibrium}

Expressing the system in terms of the stationary "scale-adjusted" per capita variables defined in (8a), together with the price of capital, $q$, the equilibrium dynamics are now expressed by:

$$
\frac{\dot{c}}{c}=\frac{\left(r[z / k]\left(1+\tau_{z}\right)-\rho-\gamma n\right)}{1-\gamma}-\left(\frac{\sigma_{N}}{\left(1-\sigma_{K}\right)}\right) n \equiv \psi-g
$$

\footnotetext{
${ }^{7}$ Using $\lambda_{i}=N \lambda$, (6a') can be written as $C^{\gamma-1} / N^{\gamma}=\lambda\left(1+\tau_{c}\right)$, which differs from (6a) by the consumption tax factor $\left(1+\tau_{c}\right)$. The optimality condition (4a') is derived as follows. The individual's optimality condition with respect to debt is $\rho-\lambda_{i}^{Y} / \lambda_{i}=\left(1+\tau_{z}\right) r-n$. Combining this with $\lambda_{i}^{Y} / \lambda_{i}=n+\lambda / \lambda$ yields the expression (4a').
} 


$$
\begin{aligned}
& \frac{k^{Y}}{k}=\left\lfloor\left(\frac{q-1}{h}\right)-\left(\frac{\sigma_{N}}{1-\sigma_{K}}\right) n\right\rfloor=\phi-g \\
& \dot{q}=r[z / k]\left(1+\tau_{z}\right) q-(q-1)^{2} / 2 h-\left(1-\tau_{y}\right) \alpha \sigma k^{\sigma_{K}-1} \\
& \dot{Y}=(r[z / k]-g) z-\alpha k^{\sigma_{K}}+c+\left(\left(q^{2}-1\right) / 2 h\right) k
\end{aligned}
$$

Eicher and Turnovsky (1999b) have characterized the aggregate dynamics of this decentralized system in detail. Linearizing around the steady state, they have shown that under weak conditions the system is saddlepath stable (with two stable eigenvalues). ${ }^{8}$

The key components of the dynamics are the solutions for $k$ and $z$, which are of the form:

$$
\begin{aligned}
& k(t)=\tilde{k}+B_{1} e^{\mu_{1} t}+B_{2} e^{\mu_{2} t} \\
& z(t)=\tilde{z}+B_{1} v_{21} e^{\mu_{1} t}+B_{2} v_{22} e^{\mu_{2} t}
\end{aligned}
$$

where: (i) $\mu_{1}, \mu_{2}$, with $\mu_{2}<\mu_{1}<0$ denote the two stable eigenvalues; (ii) $\left(1, v_{2 i}, v_{3 i}, v_{4 i}\right)(i=1,2)$ is the normalized eigenvector associated with the stable eigenvalue, $\mu_{i}$, and (iii) $B_{1}, B_{2}$ are arbitrary constants, obtained from initial conditions. Specifically, assuming that the economy starts out from an initial steady-state equilibrium having stocks of capital and debt, $k_{0}, z_{0}$, and letting $d \tilde{k} \equiv \tilde{k}-k_{0}, d \tilde{z} \equiv \tilde{z}=z_{0}$, denote the changes in the long-run equilibrium, $B_{1}$ and $B_{2}$ are given by

$$
B_{1}=\left(d \tilde{z}-v_{22} d \tilde{k}\right)\left(v_{22}-v_{21}\right) ; B_{2}=\left(v_{21} d \tilde{k}-d \tilde{z}\right) /\left(v_{22}-v_{21}\right)
$$

The constants $B_{1}, B_{2}$ thus depend upon the specific shocks, and once determined, the dynamics of $k$ and $z$ follow from (13). These depend critically upon $v_{2 i}, v_{3 i}$, which Eicher and Turnovsky show are given by

$$
v_{3 i}=h \mu_{i} / \tilde{k}<0 \text { and } v_{2 i}=-\left(a_{31}+\left(\left(1-\tau_{z}\right) \tilde{r}-g-\mu_{i}\right)(h / \tilde{k}) \mu_{i}\right) /\left(\tilde{r}\left(1-\tau_{z}\right)(\tilde{q} / \tilde{z})\right)
$$

\footnotetext{
${ }^{8}$ The simplest condition to ensure a unique stable saddlepath is $C / Y>\left(1-\sigma_{K}\right)$
} 
with $a_{31} \equiv-\left(1-\tau_{z}\right) \tilde{r}^{\prime}[.] \tilde{z} \tilde{q} / \tilde{k}^{2}+\alpha \sigma_{K}\left(1-\sigma_{K}\right) \tilde{k}^{\sigma_{K}-2}$. In general, $v_{2 i}$ can be positive or negative. A weak condition for $v_{22}>v_{21}>0$ is that the elasticity of the debt supply function exceeds $1-\sigma_{K}$. This condition establishes a relationship between the elasticities of the marginal productivities of foreign debt and capital. In general, the slope along the transitional path in $z-k$ space is given by:

$$
\frac{d z}{d k}=\frac{\left(B_{1} v_{21} \mu_{1} e^{\mu_{1} t}+B_{2} v_{22} \mu_{2} e^{\mu_{2} t}\right)}{B_{1} \mu_{1} e^{\mu_{1} t}+B_{2} \mu_{2} e^{\mu_{2} t}}
$$

For the specific case of a shock to $\tau_{z}, d \tilde{k}=0$, and (14) simplifies to ${ }^{9}$

$$
\frac{d z}{d k}=\frac{\left(v_{21} \mu_{1} e^{\mu_{1} t}-v_{22} \mu_{2} e^{\mu_{2} t}\right)}{\mu_{1} e^{\mu_{1} t}-\mu_{2} e^{\mu_{2} t}}
$$

The key point to observe is that both at $t=0, t \rightarrow \infty, d z / d k>0$, so that the transitional adjustment begins its transition and converges to its new steady state in a positive direction, as drawn in Fig. 1. Since the long-run stock of capital is unchanged, this must imply the transitional loop having capital flow reversals.

\section{Optimal Policy for Financial Market Liberalization}

We are now in the position to discuss the means by which a centrally planned economy might be able to decentralize and to introduce financial liberalization. To do so we can see that the dynamics of the centrally planned and decentralized economies are of the same general structure. First, we have seen that the aggregate debt accumulation equation, (9d), and the aggregate capital accumulation equation, (9b), are identical in the two economies. Comparing (9a') to (9a) and (9c') to (9c) we see that the rates of return to consumption, capital accumulation and debt costs will be the same, and therefore the dynamics of the decentralized economy will mimic that of the centrally planned economy, if and only if:

\footnotetext{
${ }^{9}$ This can be shown by considering the steady-state equilibrium conditions; see Eicher and Turnovsky (1999b).
} 


$$
r[Z / K]\left(1+\tau_{z}\right)=r[Z / K]+r^{\prime}[z / k](z / k)
$$

$$
\left(1-\tau_{y}\right) \alpha \sigma k^{\sigma_{K}-1}=r^{\prime}[z / k] \cdot(z / k)^{2}+\alpha \sigma_{K} k^{\sigma_{K}-1}
$$

From (15a) and (15b) we know that the decentralized economy must impose an income and a debt tax in order to replicate the first-best optimum of the centrally planned economy. From these two equations we find that the resulting optimal taxes are

$$
\begin{aligned}
\tau_{z} & =\frac{r^{\prime}[z / k](z / k)}{r[z / k]} \\
\tau_{y} & =-\left(\frac{\eta}{\sigma}+\frac{r^{\prime}[z / k] \cdot(z / k)^{2}}{\alpha \sigma k^{\sigma_{K}-1}}\right)
\end{aligned}
$$

Both optimal taxes are time-varying, changing as $z$ and $k$ evolve along their transitional paths. In the long run, as $z, k$ converge to $\tilde{z}, \tilde{k}$, the optimal tax rates converge to corresponding constant rates.

This optimal tax structure reflects the two externalities facing the economy. The first is the production externality, due to the fact that the private marginal product of capital, $\sigma$, misrepresents the true social product of capital by the amount of the externality $\eta$. In the event that this is positive, capital should be subsidized, and if negative, should be taxed, in order for the first-best optimum to be attained.

The upward sloping supply curve of debt introduces a second externality, internalized by the central planner, but ignored by the representative agent in the decentralized economy. This has a further impact on the optimal tax policy. Specifically, agents in the decentralized economy fail to take account of the fact that as they collectively increase their amount of borrowing, they raise the aggregate debt-capital ratio, thus raising the cost of debt. Similarly, as they invest in capital and increase the productive capacity of the economy and its ability to service debt, they lower the aggregate debt-capital ratio, and reduce the cost of debt. Accordingly, by underestimating the true 
cost of borrowing and underestimating the true benefits to accumulating capital the agents in the decentralized economy underinvest in capital and overborrow, relative to the first best optimum. To correct for this misallocation requires that the costs of debt be taxed at a rate which in fact is precisely equal to the elasticity of the interest rate with respect to the debt-equity ratio, while the return to capital should be subsidized.

Given the optimal tax rates as given in (16a) and (16b), a consumption tax and/or lump sum transfer is in general necessary in order for the government to maintain its balanced budget (12). With an inelastic labor supply, the consumption tax functions like the lump sum transfer, $T$, which without any loss of generality can be set arbitrarily to zero. Substituting (16a, (16b), and $T=0$ into (12) we find

$$
\tau_{c}=\frac{1}{\sigma c}\left\lfloor\alpha k^{\sigma_{K}} \eta+\frac{r^{\prime} z^{2}}{k}(1-\sigma)\right\rfloor>0
$$

which implies that consumption is taxed in the economy, both to decrease consumption financed by foreign capital, and to alter the incentives and increase domestic accumulation of capital to expand the domestic asset base.

\subsection{Financial Liberalization and Capital Flow Reversals}

Having derived the first-best optimal tax structure enables us to discuss the optimal transition of an economy from one having state-controlled financial intermediation to one allowing private individuals to determine the levels of investment and borrowing. In such a transition from a centralized system of international borrowing to a decentralized system, policy makers must take into account that the country-specific borrowing rate is a function of its credit worthiness - an aspect that individuals neglect. If credit worthiness is determined by the amount of debt relative to performing assets, decentralization without appropriate taxation can lead to capital inflow reversals.

During the financial liberalization process, the government must thus impose at least two fiscal measures to correct for the two externalities facing the economy and to avoid subsequent capital flow 
reversals: a tax on foreign borrowing, a subsidy on domestic capital formation. A tax on consumption may also be necessary, but only to balance the fiscal budget. If the financial liberalization occurs with the tax rates on capital, debt, and consumption set in accordance with (16) and (17) the economy will not experience any change in the level of any of its variables. This is because these tax rates ensure that the decentralized economy perfectly replicates the equilibrium of the central planner.

However, if the tax on debt is set insufficiently high at the start of the financial liberalization, the country will accumulate excess debt and go through a boom-bust and capital flow reversal. This dynamic adjustment is generated by the nonlinear stable transitional path of the decentralized economy. One can show from (13) and (14) that a lowering of the tax on foreign borrowing will lead to an initial increase in both investment and debt accumulation, as $d z /\left.d k\right|_{t=0}>0$. On the other hand, we know that the new equilibrium will be approached by an economy with declining capital stock and debt levels, as again from (14) it can be shown that $d z /\left.d k\right|_{t=\infty}>0$. These dynamics imply a reversal of the growth boom and capital outflows as the economy attains its new equilibrium.

The intuition for the transition loop in $z-k$ space coincides with the three segments in Figure 1. The first segment is a borrowing boom that refers not only to the increase in debt, but also to the increase in capital accumulation and to the transitional growth that it finances. The immediate effect of a higher debt subsidy is to lower the net costs of borrowing but increase the relative shadow value of capital, $q$. The reduced borrowing costs and the increased shadow value of capital lead to increased debt and capital accumulation. The period of the debt financed growth boom is during the initial phase of decentralization without exact taxation is shown in the move from PQ in Fig 1.

The second segment is an interest crunch, which occurs as the increased debt service cost ever leaves less output for investment. The rate of capital accumulation slows and eventually starts to decline. The growth boom comes to a halt. However, debt continues to flows into the country to finance consumption as the economy moves from $\mathbf{Q R}$ in figure 1.

Finally the country experiences capital flow reversal. Eventually the increase in debt raises debt costs due to the upward sloping supply curve of debt. Country risk has increased since the debt to capital ratio has risen. Then the country finds it necessary to tighten the belt and reduce capital 
expenditures and debt as it approaches a new equilibrium, one represented by the movement along the final segment $\mathbf{R S}$ toward the new steady-state equilibrium at $\mathbf{S}$. Note that neither the long run level of capital, nor the long run growth rate is altered, due to the non-scale nature of the model. In this case the rate of growth of capital and output are determined exclusively by the production characteristics. This implies from the steady state conditions that also the scale-adjusted level of capital is also not altered. ${ }^{10}$

\section{Country Evidence}

In this section we compare the implications of our theoretical model with the experience of some countries in which capital flow reversals actually occurred. The 1990s, most notably the first half of the decade, were characterized by massive capital flows to developing countries leading to progressive financial integration of developing countries into world financial markets. We look at the most prominent examples of capital flow reversals during this period: Thailand, Indonesia, South Korea, and Mexico. ${ }^{11}$ These four countries are among the eight largest recipients of private capital flows into developing countries in the first half of the 1990s (see World Bank (1997, p.12)) indicating the importance of these cases. We look into the most recent economic history of these countries, characterize their activities with respect to financial integration, illustrate their accumulation of domestic investment as well as of their foreign debt, and compare it to the predicted time path emerging from our model. We start with the Asian countries and discuss them in the sequence in which the crises occurred.

\subsection{Thailand}

\footnotetext{
10 The fact that the long run level of capital does not change as the tax on debt changes can be ascertained by solving (14) and (9) for the steady state levels of capital.

11 Other examples for (private) capital flow reversals in the 1990's include Turkey (1993-94), Venezuela (1992-94), Chile (1990-91) (see World Bank (1997) as well as Brazil (1998-9). While we suspect the Brazilian case to comply with our story, due to the lack of these rather recent data, we were unable to examine this case.
} 
Thailand has been one of the most important recipients of capital inflows among the developing countries. The level of foreign debt almost tripled in only 5 years between 1992 to 1996. In these years net capital inflows ranged from 9-13 per cent of GDP (see IMF (1998)). Whereas initially foreign direct investment contributed a large share of capital inflows, portfolio investments became increasingly important.

Financial liberalization preceded these developments in Thailand. Interest rates and credit controls were liberalized gradually in 1990 and in 1992 the ceilings on saving deposits and lending rates were removed. Since the late 1980s the range of permissible activities of commercial banks were substantially broadened and the asset holdings requirements were liberalized. In 1993 the entry of foreign banks into the Thai market was facilitated (see Dekle/Pradhan (1997)). With respect to capital account liberalization, several rounds of relaxation of foreign exchange regulations were introduced which were completed in 1992 with the fourth round. In 1992 in an effort to induce foreign investment in the Thai stock market, a number of taxes on assets of foreigners in Thailand were reduced, most importantly, capital gains taxes, taxes on interest payments from debentures to foreign juristic persons, as well as taxes on dividends remitted abroad. A year earlier, the repatriation of loan and interest payments of foreigner had completely become liberalized (see IMF (1998, p. 101)). At the same time, the Thai government initiated an incentive program aimed at promoting regional development outside of Bangkok, which was financed to a large part by foreign capital. The incentives include an eight-year holiday from corporate taxes and exemptions from tariffs on imported capital (see Asian Development Bank (1995)).

Against this background we look at the evolution of Thailand's performance during the years after 1992. In order to be able to compare the Thai case to the predictions of the model we focus on (as we will also with the other countries) the evolution of foreign debt (z) as well as on the domestic capital stock $(k)$. For the level of foreign debt we use the level of debt as given in the IMFs Global Finance and measure the increase in debt with the current account deficit. Using quarterly current account data of the International Finance Statistics, we get a debt series with quarterly observations. With respect to domestic capital accumulation we geometrically extrapolate the International Institute 
of Finance (IIF)'s yearly data on gross fixed investment to get a quarterly series of the evolution of the domestic capital stock. The result of this procedure is plotted in Figure 2a.

As the figure reveals, the time path predicted by the model and one actually observed in the Thai case are strikingly similar. Financial liberalization was followed by a borrowing boom; that is, foreign borrowing was accompanied by domestic capital accumulation (above historical levels) implying that inflowing capital was used for investment rather than for consumption. In 1997 the first reversal too place with negative investment rates and a decrease in the national capital stock. At the end of 1997/ beginning of 1998, that is, after the culmination of the crisis, capital inflows reversed and $z$ decreased, bringing about a sharp recession in Thailand.

In order to analyze the proposed mechanism of the capital flow reversals in more detail, we take a look at the evolution of real rates in the countries under consideration. As we want to capture the change in the cost of capital and foreign debt for the country at a given period of time, we use the short term interest rate in local debt which is deflated with the national CPI-index available from the International Financial Statistics of the IMF. It turned out that money market rates were most appropriate for our objective (other short-term interest rates were partially distorted by too little variability caused by institutional constraints). We use monthly data on money market rates (3 month money market rates) also available from the IMF's International Financial Statistics for all our countries.

For the Thai case we find that the trend of real interest rates was upward, moving from slightly below 5 per cent in 1993 (on average) to more than 10 per cent in 1998. This trend was from time to time interrupted by sharp upward- or downward movements of rates which, however, reflect partially only measurement problems associated with the concept of the real rate and partially also spillover effects from crisis in other developing countries (e.g. the Tequila effect in 1995). The upward trend of real interest rates (which is associated with an upward in the spread over (real) LIBOR) is, however, a strong indication in favor of our mechanism. With an increasing debt/capital ratio the spread over worldwide interest rates increases, leading to higher interest rate payments. 


\subsection{Indonesia}

At the end of the 1980's Indonesia maintained a liberal regime for capital outflows while prohibiting lending abroad by banks and financial institutions. In 1989, the authorities liberalized portfolio capital inflows for a short period of time by eliminating among other things quantitative limits on banks' borrowing from nonresidents. Foreigners were allowed to acquire up to 49 per cent of the ownership of stocks listed at the Indonesian stock market. Restrictions on direct investment inflows were also relaxed leading to easier and less costly inflow of foreign direct investment and portfolio capital (see IMF (1998)). These measures of financial liberalization were, however, suspended in 1991 and once again came into effect in 1992/93. Limitations on public sector borrowing remained in place from 1992 to 1996. During this period, the banking sector was deregulated, too. In 1988, relaxation of entry requirements of domestic and joint venture banks were relaxed leading to an increase of the total number of banks from 111 banks in 1989 to 240 in 1994 (see Dekle/Pradhan (1997)).

Against this entire background we start our observations in 1994 (see figure 2b). We used the same procedure and the same data sources as with the Thai case. We find a similar pattern as in the Thai case. A period of rapid accumulation of domestic capital and foreign borrowing coupled with real growth rates of per capita income exceeding the long-run trend is followed by a slow-down of capital accumulation. Inspection of interest rate spreads (Indonesian money market rates over LIBOR) reveals that during this period this interest rate spread has a positive trend. In the final period we observe (see Figure 2b) an outflow of foreign capital and a rather sharp recession.

\subsection{South Korea}

Whereas one could argue for obvious contagion effects for the Indonesian case resulting from Thailand's crisis, this is not possible for the Korean case. This is because Korea is geographically quite distant from these two economies and also quite different from them in economic terms (i.e. 
with respect to income as well as production and trade patterns). Hence, Korea can be seen as an interesting "test" of our theoretical approach.

During the 1980s and even the beginning of the 1990s the Korean economy was characterized by significant government intervention and a financial sector, which lagged behind the real sector of the economy. Financial liberalization was quite gradual and a comprehensive plan was not adopted before 1992. Among the detailed measures adopted in this period was an opening of the domestic stock market to foreign investors, subject, however, still to some limitations (see World Bank (1998)). The types of securities that could be issued abroad were significantly expanded. Furthermore, a large number of markets and sectors were opened to foreign portfolio investments and regulations on foreign exchange transactions were liberalized. Most of this took place in 1992/93. All this led to a pronounced inflow of private capital after 1994 consisting in large parts of foreign direct investment. As in the two other countries foreign capital was used to invest domestically bringing about a pronounced increase in investment growth. In 1997 the investment boom came to a halt and investment growth rates even turned negative. Finally in the last quarter of 1997 capital outflows took place at a significant level coupled with a sharp deterioration of the Korean won (see Figure 2c).

\subsection{Mexico}

The years 1989-1992 were characterized by economic reforms in the financial sector. Deregulation of the financial sector was one of the cornerstones of this program. In this framework banks were gradually privatized after 1990. For the first time, banks were allowed to hold equity positions in manufacturing and other firms. Despite these liberalization steps, regulatory and supervisory capacities remained weak (see Edwards (1996)).

All this led to an inflow of huge amounts of foreign capital, which fueled a consumption boom but also led at to a modest increase of the rate of investment (see Figure 2d). Most of foreign capital inflows where short term portfolio investments. At the end of 1994, reinforced by domestic problems, the Peso-crisis occurred leading to a currency crisis a sharp recession coupled with a sharp fall in 
investment rates. Following the crisis, the inflow of foreign capital dried up. In some quarters (e.g. Q2/95) foreign debt even decreased slightly.

\section{Conclusions}

Foreign capital flow reversals have been an important phenomenon during recent years in a number of developing economies. The objective of this paper has been to develop a growth model that is capable of yielding such reversals as part of the intrinsic dynamics generated by specific policy events, in particular financial liberalizations that have taken place recently. In order to generate this behavior the transitional dynamics must be represented by a higher order system than that generated by the standard endogenous growth model of a small open economy. The main contribution of this paper is to show how such behavior can arise very naturally in a simple non-scale growth model of an economy facing the kind of world capital market imperfection that small developing economies realistically encounter. Throughout our discussion, capital flow reversals are the result of suboptimal financial liberalization. This is a consequence of the fact that we start from an optimally planned central economy. However, a loop also arises if, starting from too high a level of taxes on foreign debt, the tax rate is lowered. In this case, capital flow reversals would also arise, but would now be the result of an optimal financial liberalization.

The country evidence presented supports our theoretical story and the explanation of capital flow reversals: suboptimal financial liberalization. There are without doubt other explanations to capital flow reversals (e.g. policy switches) and financial liberalization does not necessarily lead to capital flow reversals (see e.g. the case of Chile in the late 1980s). But our evidence reveals that financial liberalization can be a source of capital flow reversals. Hence, by designing financial reforms governments must take into account that financial liberalization might also be too far-reaching leading to the risk of capital flow reversals and the associated impact on the domestic economy. 


\section{REFERENCES}

Aizenman, J.A. and S.J. Turnovsky, "Reserve Requirements on Sovereign Debt in the Presence of Moral Hazard - On Debtors or Creditors?” NBER Working paper \#7004, (1999).

Asian Development Bank, Asian Development Outlook, 1995 and 1996, (1995).

Backus, D., P. Kehoe, and T. Kehoe, "In Search of Scale Effects in Trade and Growth,” Journal of Economic Theory 58 (1992): 377-409.

Bardhan, P.K., “Optimum Foreign Borrowing,” in K. Shell (ed.), Essays on the Theory of Optimal Economic Growth, Cambridge, MA: MIT Press, (1967).

Bhandari, J.S., N. U. Haque, and S.J. Turnovsky, “Growth, External Debt, and Sovereign Risk in a Small Open Economy," IMF Staff Papers 37 (1990): 388-417.

Bond, E.W., P. Wang, and C.K. Yip, "A General Two-Sector Model of Endogenous Growth with Human and Physical Capital: Balanced Growth and Transitional Dynamics,” Journal of Economic Theory 68 (1996): 149-173.

Cooper, R.N. and J. Sachs, "Borrowing Abroad: The Debtor's Perspective," in G.W. Smith and J. T. Cuddington (eds.), International Debt and Developing Countries, Washington, DC: World Bank, (1985).

Dekle, R. and M. Pradhan, "Financial Liberalization and Money Demand in Asean Countries: Implications for Monetary Policy", IMF Working Papers 36 (1997).

Eaton, J. and M. Gersovitz, "Debt with Potential Repudiation: Theoretical and Empirical Analysis," Review of Economic Studies 48 (1981): 289-309.

Eaton, J. and M. Gersovitz, "Country Risk and the Organization of International Capital Transfer," in G. Calvo, R. Findlay, P. Kourri, and J. Braga de Macedo (eds.) Essays in Memory of Carlos Diaz-Alejandro, Blackwell, Oxford (1989).

Edward, S. "LDC Foreign Borrowing and Default Risk: An Empirical Investigation, 1976-1980," American Economic Review, 74, (1984): 726-34. 
Edwards, S. "A Tale of Two Crises: Chile and Mexico," NBER Working Paper, No. 5794, Oct. (1996)

Eicher, T.S. and S.J. Turnovsky, "Non-scale Models of Economic Growth," Economic Journal (1999a) forthcoming.

Eicher, T.S. and S.J. Turnovsky, "International Capital Flows and Non-Scale Growth," Review of International Economics, 7 (1999b): 171-188.

Fisher, W., "An Optimizing Analysis of the Effects of World Interest Rate Disturbances on the Open Economy Term Structure of Interest Rates," Journal of International Money and Finance 14 (1995): 105-126.

Fischer, S., "Economics and the Financial Sector," Speech to the Federal Deposit Insurance, (9/10/1998).

Guitian, M., "The Challenge of Managing Global Capital Flows," Finance and Development, 35 (1998)

International Monetary Fund (IMF), "Sequencing Capital Account Liberalization: Lessons from Experiences in Chile, Indonesia, Korea and Thailand," IMF Working Paper No. 97/157 (1998).

Jones, C., "R\&D Based Models of Economic Growth,” Journal of Political Economy 103 (1995a): 759-784.

Jones, C., "Time Series Tests of Endogenous Growth Models," Quarterly Journal of Economics 110 (1995b): 495-527.

Kletzer, K.M., "Asymmetries of Information and LDC Borrowing with Sovereign Risk," Economic Journal 94 (1984): 287-307.

Obstfeld, M., "Aggregate Spending and the Terms of Trade: Is There a Laursen-Metzler Effect?" Quarterly Journal of Economics 97 (1982): 251-270.

Ploeg, F. van der, "Budgetary Policies, Foreign Indebtedness, the Stock Market, and Economic Growth," Oxford Economic Papers 48 (1996), 382-396. 
Romer, P.M. "Increasing Returns and Long-Run Growth," Journal of Political Economy 94 (1986): 1002-38.

Sachs, J., "Theoretical Issues in International Borrowing," Princeton Studies in International Finance 54 (1984).

Segerstrom, P., "Endogenous Growth without Scale Effects," American Economic Review 88 (1998): 1290-1311.

Solow, R.M., "Perspectives on Economic Growth," Journal of Economic Perspectives 8 (1994): 4554.

Stokey, N. and S. Rebelo, "Growth Effects of Flat-Rate Taxes," Journal of Political Economy, 103 (1995): 519-50.

Turnovsky, S.J., "Fiscal; Policy, Growth, and Macroeconomic Performance in a Small Open Economy," Journal of International Economics, 40 (1996): 41-66.

Turnovsky, S.J., International Macroeconomic Dynamics, MIT Press, Cambridge MA, (1997).

World Bank, Private Capital Flows to Developing Countries, Oxford University Press $(1997,1998)$

Young, A., "Growth without Scale Effects," Journal of Political Economy 106 (1998): 41-63. 
Figure 1

Capital (k) And Debt (z) Flows After Financial Liberalization With Insufficiently High Tax On Foreign Borrowing

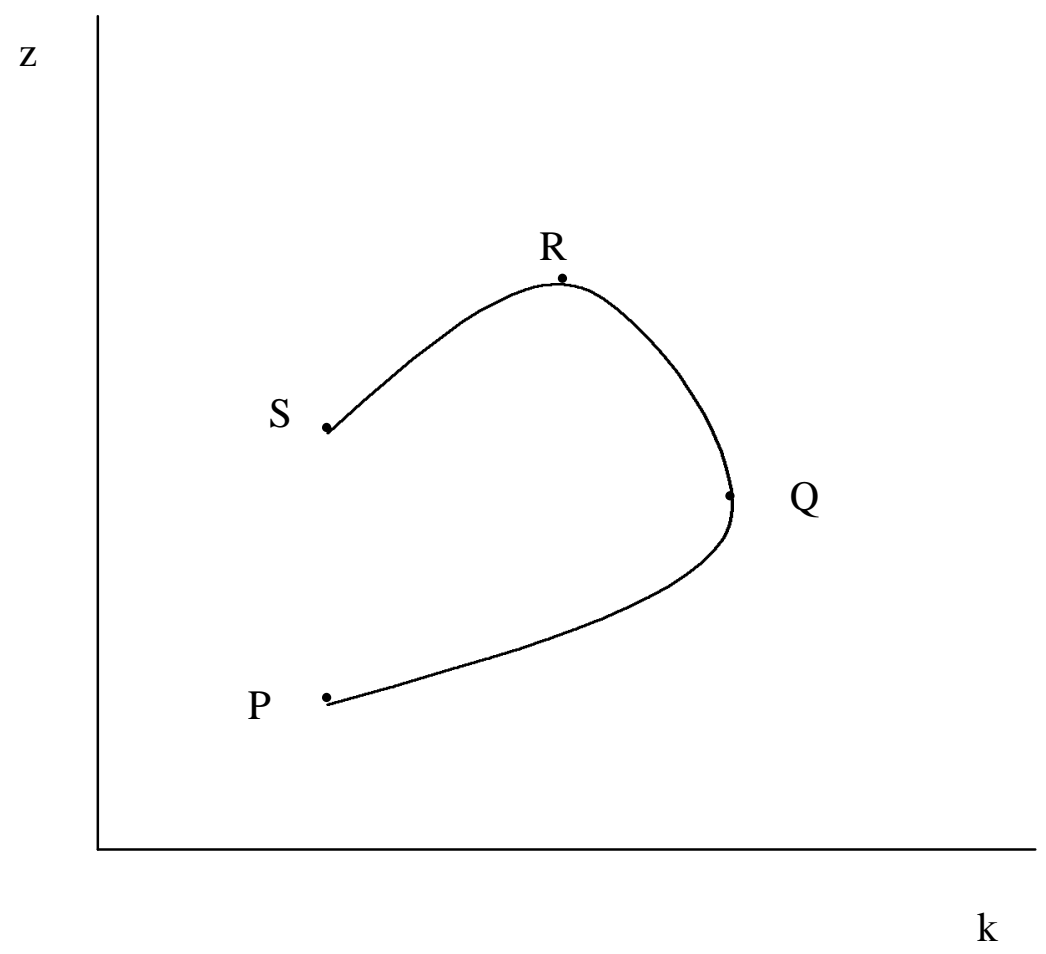


Thailand (a)

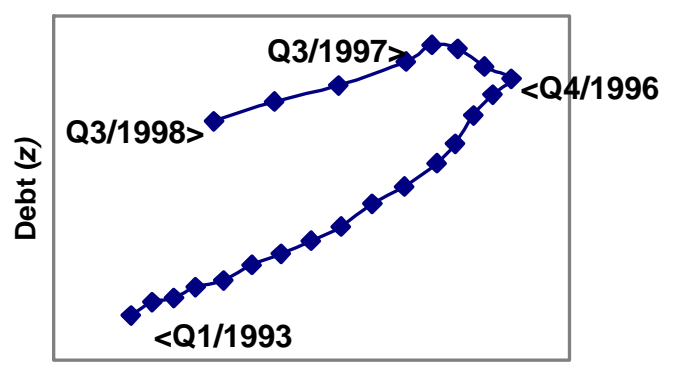

Capital Stock (k)

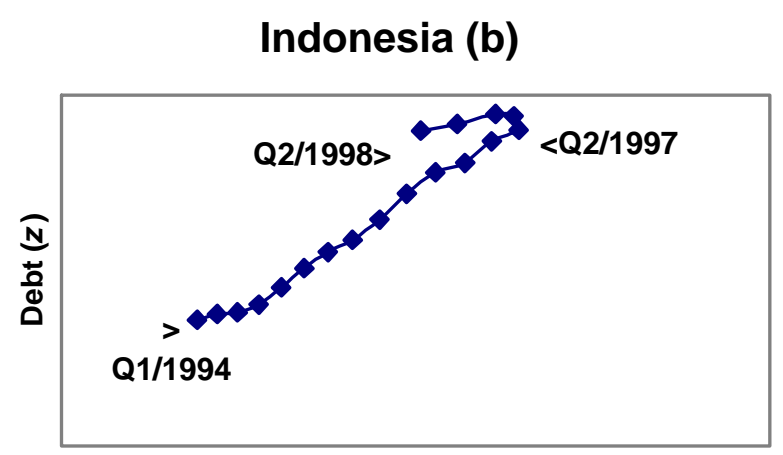

Capital Stock (k)

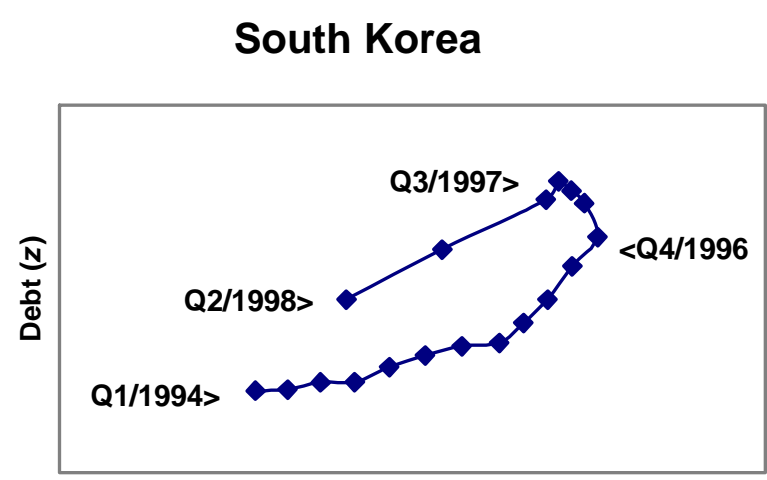

Captial Stock (k)

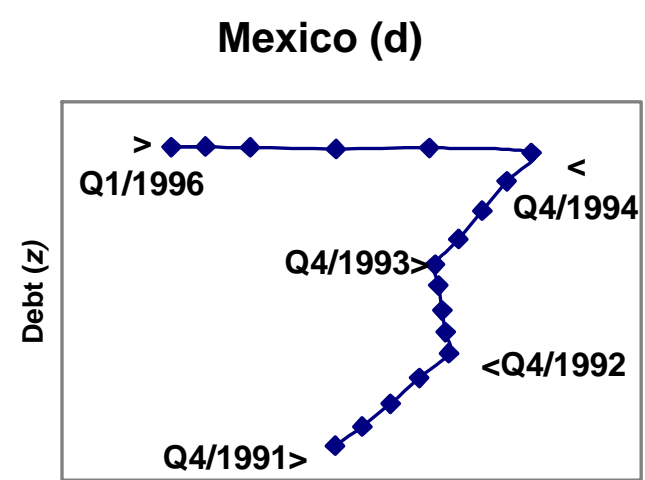

Capital Stock (k)

Figure 2

Quarterly Debt vs. Capital 